\title{
1 Characterization of a sustainable sulfur polymer concrete using activated 2 fillers
}

4 Juhyuk Moon ${ }^{\mathrm{a}, *}$, Paul D. Kalb ${ }^{\mathrm{b}}$, Laurence Milian ${ }^{\mathrm{b}}$, Paul A. Northrup ${ }^{\mathrm{c}}$,

$5 \quad{ }^{a}$ Civil Engineering Department, Stony Brook University, NY 11794, USA

$6{ }^{\mathrm{b}}$ Biological, Environmental and Climate Sciences Department, Brookhaven National Laboratory, Upton, $7 \quad$ NY 11973, USA

$8 \quad{ }^{\mathrm{c}}$ Photon Sciences Directorate, Brookhaven National Laboratory, Upton, NY 11973, USA

9

* Corresponding author. Phone: +1-631-632-9222, Postal address: 250 Heavy Engineering, Stony Brook University, Stony Brook, NY 11794, E-mail address: juhyuk.moon@stonybrook.edu

\section{Abstract}

Sulfur polymer concrete (SPC) is a thermoplastic composite concrete consisting of chemically modified sulfur polymer and aggregates. This study focused on the characterization of a new SPC that has been developed as a sustainable construction material. It is made from industrial by-product sulfur that is modified with activated fillers of fly ash, petroleum refinery residual oil, and sand. Unlike conventional sulfur polymer cements made using dicyclopentadiene as a chemical modifier, the use of inexpensive industrial by-products enables the new SPC to cost-effectively produce sustainable, lowcarbon, thermoplastic binder that can compete with conventional hydraulic cement concretes. A series of characterization analyses was conducted including thermal analysis, X-ray diffraction, and spatiallyresolved X-ray absorption spectroscopy to confirm the polymerization of sulfur induced from the presence of the oil. In addition, mechanical testing, internal pore structure analysis, and scanning electron microscope studies evaluate the performance of this new SPC as a sustainable construction material with a reduced environmental impact. 


\section{Introduction}

Portland cement requires the heating of limestone in kilns at temperatures of more than $1400^{\circ} \mathrm{C}$ for hours to form clinker materials. Because of the fossil fuel burned to power the kilns and the stoichiometric carbon dioxide emission from the conversion of limestone to calcium oxide, the process generates about one ton of carbon dioxide per each ton of cement and accounts for $5 \%$ of the global anthropogenic generation of $\mathrm{CO}_{2}[1,2]$. In contrast to traditional cement manufacturing, the production of sulfur based cement does not rely on heavy energy input or direct carbon dioxide emission [3-5]. In addition, sulfur is in net surplus on a global basis. Sulfur is the third most abundant chemical element in petroleum at concentration of over $10 \mathrm{wt} . \%$ and its recovery from petroleum and gas processing is mandated under environmental restrictions [6]. Thus, large quantities of sulfur are available as byproducts of these processes [3]. Moreover, since sulfur itself is an industrial by-product, significant amount of carbon dioxide emission can be reduced by using sulfur based concrete.

Sulfur based concrete is a thermoplastic composite of mineral aggregates and sulfur. Early studies using elemental sulfur revealed that it has serious durability problems such as under repetitive cycles of freezing and thawing [7-10]. When sulfur and aggregate are hot-mixed and cooled to cast sulfur concrete products, the liquid sulfur binder initially crystallizes to monoclinic sulfur $\left(\mathrm{S}_{\beta}\right)$. As it continues to cool, the material goes through a solid phase transition to orthorhombic sulfur $\left(\mathrm{S}_{\alpha}\right)$, which causes the material to shrink in volume. This reduction in volume creates internal stress and causes durability problems, especially when exposed to freeze-thaw cycling. Therefore, chemical modifiers that polymerize the sulfur to reduce or eliminate the solid phase transition and thus enhance the durability of sulfur based concrete have been previously studied $[3,11,12]$. This modified sulfur concrete is called sulfur polymer concrete (SPC). It has been used as a construction material due to its superior resistance to acid and salt environments. This binder is also known to effectively stabilize/solidify contaminated soils $[13,14]$ or nuclear waste $[4,15,16]$. Unlike conventional hydraulic cement concretes, the SPC needs no water and can achieve full strength in several days, compared with up to 28 days for conventional portland cement based concretes.

Several organic chemical modifiers have been developed to effectively polymerize sulfur. The commonly used modifiers are dicyclopentadiene (DCPD), a combination of DCPD, cyclopentadiene and 57 dipentene $[10,17,18]$, olefinic polysulfide [9, 19], and 5-ethylidene-2-norbornene (ENB) and/or 5-vinyl58 2-norbornenen (VNB) [3]. When processed with molten sulfur, unsaturated hydrocarbons in the organic 59 modifiers break up liquid $\mathrm{S}_{8}$ rings and react to form long chain polymers. The polymerized linear sulfur 60 chains improve durability. Although the modified concrete is environmentally sustainable and durable, 
61

62

63

64

65

66

67

68

69

70

71

72

73

74

75

\section{6}

77

the high cost for these organic modifiers has prevented it from being widely used in the construction industry [11].

This paper describes the development and characterization of a new modified SPC based on a patented process developed at Brookhaven National Laboratory (BNL) [20]. Instead of the expensive organic modifier, the process uses an industrial by-product of petroleum distillation (i.e., light catalytic cracking oil) as a sulfur modifier. Along with this modifier, another waste product, fly ash, (e.g., from coal power plants) and sand are used to provide reactive surface area and as physical filler materials in the SPC. Since most of the main ingredients for the new SPC are industrial by-products (i.e., sulfur, fly ash, and petroleum distillate), this low-cost solution is expected to expand the use of SPCs and significantly reduce the environmental impact in the construction sector. This study has focused on material characterization of the new SPC. Mechanical and thermal testing, crystallographic analysis, and microscopic analysis have been performed to evaluate the feasibility of using the material for construction applications. In addition, spatially-resolved X-ray absorption spectroscopy was firstly applied to identify heterogeneously distributed modified sulfur in the developed SPC.

\section{Experimental Method}

\subsection{Characterization of light catalytic cracking oil}

Characterization of the light catalytic cracking oil was conducted by an independent laboratory according to ASTM Method D5554-15 which is to determine the number of unsaturated hydrocarbons available for reaction with sulfur to confirm the potential for polymerization [21]. The iodine value is a measure of the unsaturation of fats and oils and is expressed in terms of the number of centigrams of iodine absorbed per gram of sample as a result of the procedure, i.e., the amount of iodine that completely reacts with $100 \mathrm{~g}$ of the fat/oil [21]. Analysis of two replicates each, for four samples was conducted resulting in a mean iodine value of $51.9 \pm 4.7$. Furthermore, initial, final, and fractional distillation point temperatures were measured according to ASTM D86-12 [22] and summarized in Table 1.

\subsection{Material synthesis}

SPC fabrication includes pre-treatment of the filler materials (Type F fly ash from a coal-fired power plant and fine quartz aggregate) with the light catalytic cracking oil followed by processing with 
elemental sulfur to form the polymerized sulfur mortar. A mix design proportion of $54 \mathrm{wt} . \%$ sand, $18 \mathrm{wt} . \%$ fly ash, 26 wt.\% sulfur, and 2 wt.\% organic modifier was selected (Table 2). While fly ash is used in ordinary cement concrete for its pozzolanic reaction which allows a reduction in the product's carbon footprint, the fly ash in SPC (along with sand) is used to provide potential reaction sites for polymerization and as a filler component in the composite material. It has been also reported that the addition of fly ash in SPC is beneficial for increasing the consistency and workability of the mixture due to its round shape and appropriate size as a filler material [11, 23]. Fig. 1 shows scanning electron microscope (SEM) images of the elemental sulfur and fly ash particles, depicting irregular shapes of ground elemental sulfur particles and the size (about 5 microns or smaller in diameter) and spherical shapes of the fly ash particles. For the pre-treatment stage, the filler materials and organic modifier were mixed and heated to a temperature of $170-180^{\circ} \mathrm{C}$ for $12 \mathrm{hrs}$. The materials were combined with elemental sulfur and processed through a cross-beater mill with a mesh size of $1 \mathrm{~mm}$ to reduce particle size. The mixture was then heated and mixed in a molten condition at $135-145^{\circ} \mathrm{C}$ for $4-6$ hours and poured into molds for cooling. The average density of the mortar specimens was $2282( \pm 41) \mathrm{kg} / \mathrm{m}^{3}$.

\subsection{Mechanical and thermal experiments}

Mechanical and thermal experiments were performed to verify sulfur polymerization and to ensure the integrity of the product for construction applications. To evaluate the mechanical performance, compressive and three-points flexural tests were performed on $160 \times 40 \times 40 \mathrm{~mm}$ samples. The mechanical strength of the samples was determined under two conditions of $20^{\circ} \mathrm{C}$ and $50^{\circ} \mathrm{C}$. For each strength measurement, six samples were tested for a statistical assessment. The results are summarized in Table 3.

Thermal properties of elemental sulfur and SPC were measured using differential scanning calorimetry (DSC, PerkinElmer DSC 6000). To perform this test, a $30 \mathrm{mg}$ sample was loaded in an Al crucible and heated at a rate of $5^{\circ} \mathrm{C} / \mathrm{min}$ in a controlled environment with flowing inert nitrogen gas. A temperature range from 25 to $200^{\circ} \mathrm{C}$ was selected. Since there were no major temperature fluctuations below $90^{\circ} \mathrm{C}$, a temperature range of 90 to $180^{\circ} \mathrm{C}$ in both samples was used as shown in the DSC thermogram in Fig. 2.

The chemical composition of SPC and raw material of fly ash was analyzed by X-ray fluorescence (XRF, Rigaku NEX CG EDXRF Analyzer). Finely ground SPC was combined with a spectroblend binder and mixed with a mixer mill for a period of 5 minutes to ensure a homogenous mixture. An analytical pellet was formed by pressing the powder for 1 minute. A total measurement time 
of 20 min was selected to get a stable XRF signal from the samples. The measured elemental composition of SPC and fly ash is summarized in Table 4.

\subsection{Microstructural characterization}

A series of microstructural characterization studies was performed on the final product of SPC. First, mineralogical analysis for the identification and quantification of crystal phases in elemental sulfur, fly ash and SPC was achieved by quantitative X-ray diffraction (XRD). To prepare the material for this test, elemental sulfur and SPC were finely ground. For the quantification of amorphous content in the concrete and fly ash, each sample was mixed with $10 \mathrm{wt} \%$ of an internal reference material of $\mathrm{ZnO}$ (NIST SRM 674b). The mixed sample was then scanned on the Rigaku Miniflex with a range of $10 \leq 2 \theta$ $\leq 60^{\circ}$ using $\mathrm{Cu}$ radiation and a $0.033^{\circ}$ step size. The crystalline phases in the XRD pattern were identified by first subtracting the background from the raw data and then comparing Bragg peak positions and relative intensities to those from reference patterns found in the ICSD PDF database. The structures of the identified phases were used to refine the phase fractions present in the crystalline portion of the sample. Figure 3 and Table 5 show the refined XRD results and measured crystalline fractions for the sample. A detailed discussion on phase quantification will follow in the Result and Discussion section.

Micro-computed tomography (CT), which is the process of using X-rays to non-destructively image the internal structure of a sample, was applied to construct a series of $2 \mathrm{D}$ slices as well as 3D volumetric images of SPC. A concrete sample of $25 \mathrm{~mm}$ diameter and $50 \mathrm{~mm}$ height was analyzed using the SkyScan 1173 (Bruker, Germany). Obtained 2D images have a size of 1998 by 1998 pixels and a $12.5 \mu \mathrm{m} /$ pixel resolution. Identification of pores (black) was possible from the sulfur matrix (grey) as shown in Fig. 4. To differentiate pores, a threshold value of 40/256 was selected by visual inspection. Then small pores of a size of $2 \times 2 \times 2$ voxels (i.e., $100 \mu \mathrm{m}^{3}$ ) have been removed considering the noise of collected images which might affect the accuracy of following image-processing analysis. After that, binary 0 (black) and 1 (white) matrix is constructed and processed using AVIZO Fire image processing software (VSG, France). Fig. 5(a) shows reconstructed 3D volumetric images of SPC (grey) and segmented pores (blue). The segmented pores were also graphically visualized based on its volume (Fig. 5(b)). Using image processing technique (previously conducted for SEM images [24]), distributions of pore surface area and pore volume could be calculated (Fig. 6). Furthermore, the mass properties of the pores were calculated by the inertia tensor method $[25,26]$. A 3 by 3 matrix (M) was formulated as the moments of inertia $\left(\mathrm{M}_{\mathrm{XX}}, \mathrm{M}_{\mathrm{XY}}, \ldots, \mathrm{M}_{\mathrm{ZZ}}\right)$ of a considered 3D pore in the $\mathrm{x}, \mathrm{y}, \mathrm{z}$ coordinate system (Eqn. $1)$. 
Eigenvalues and eigenvectors of the matrix $M$ are equal to the principal moments (I1 $1>$ I22 $>$ I33) and principal reactions, respectively. Then, the degree of anisotropy of each pores can be calculated from Eqn. 2.

This histogram of computed anisotropy is shown in Fig. 7(a). In addition, the ratios of the principal moments of each pores (I33/I11 vs. I22/I11) are provided in Fig. 7(b).

A thin section $(200 \mu \mathrm{m})$ of SPC was prepared for SEM analysis. Fully cured sample was cut, polished, and epoxy-impregnated under vacuum condition. Before SEM measurement, gold was coated on the surface of the sample. A JEOL JEM2100F with SDD EDX detector was used for SEM-energydispersive X-ray spectroscopy (SEM-EDS) analysis. $10.0 \mathrm{keV}$ and $5 \mathrm{~mm}$ working distance were selected for secondary electron (SE) imaging. Along with the thin section sample SEM-EDS analysis, images of fly ash and elemental sulfur were obtained using a high-resolution field-emission SEM (Hitachi HD2700C, Fig. 1). Each material was dispersed on carbon tape and $5.0 \mathrm{keV}$ of voltage and $10 \mathrm{~mm}$ of working distance were chosen for optimized imaging.

The X-ray absorption near edge (XANES) spectrum provides a sensitive probe of electronic 169 structure and chemical form. Sulfur K-edge XANES spectroscopy has been used to study sulfur 170 speciation in various systems including coal, asphalt, and heavy oils [6, 27-30]. While it has become a 171 well-established method to characterize a local environment of sulfur (i.e., coordination number and 172 interatomic distance), the XANES technique has not been used in general for construction materials due 173 to its heterogeneous nature [31-33]. In this study, a spatially-resolved XANES experiment was performed 174 to verify the polymerization of sulfur and detect any changes of the local atomic environment of sulfur 175 from the reaction by a catalytic cracking oil modifier. In addition, the spatially-resolved sulfur spectra 176 were compared with the XANES spectrum of elemental sulfur. The sulfur K-edge XANES were recorded 177 in the X15B beamline at the National Synchrotron Light Source (NSLS) of Brookhaven National 178 Laboratory. X15B was equipped with a $\mathrm{Si}(111)$ monochromator, with an energy resolution of $0.2 \mathrm{eV}$ at 179 the sulfur K-edge. The XANES spectra were acquired in fluorescence mode and the sulfur K-edge 180 fluorescence was isolated from the detector spectrum. The entire sample environment was purged at 1 atm with helium gas. The spectra for both elemental sulfur and SPC were collected by scanning incident energy from 2450 to $2526 \mathrm{eV}$, with a step size of $0.2 \mathrm{eV}$ and an exposing time of $0.1 \mathrm{~s}$ for each step. Xray fluorescence microscopy method was applied for observing heterogeneous sulfur distribution and 
selecting several spot positions for XANES measurement. Ten measurements on an identical position were repeated to achieve one averaged XANES spectrum.

\section{Results and Discussion}

\subsection{Reactivity, mechanical and thermal characteristics}

The number of unsaturated hydrocarbons in the light catalytic cracking oil was determined by the ASTM D5554-15 [21]. The obtained iodine value of 51.9 \pm 4.7 . The higher the iodine value, the higher percentage of unsaturated hydrocarbons available for reaction with sulfur. This data could suggest the possibility of using the oil for sulfur polymerization and be further used to evaluate or compare the performance with other chemical activators.

Table 2 shows the results of compressive and flexural mechanical testing. Mean compressive strength for the six replicate specimens are $62.3 \pm 3.8 \mathrm{MPa}$ and $59.6 \pm 4.5 \mathrm{MPa}$ at ambient $\left(20^{\circ} \mathrm{C}\right)$ and elevated temperature $\left(50^{\circ} \mathrm{C}\right)$, respectively. The measured strength is above requirements for most construction applications and is significantly greater than typical hydraulic cement mortars. No significant degradation of strength was observed at elevated temperature condition.

The stable form of sulfur at ambient temperature is orthorhombic $\left(\mathrm{S}_{\alpha}\right)$ and the other main allotropes are monoclinic $\left(S_{\beta}\right)$ and polymeric sulfur $\left(S_{\infty}\right)$ [6]. The $S_{\alpha}$ and $S_{\beta}$ consist of $S_{8}$ rings and $S_{\infty}$ has long chains up to $10^{6}$ atoms long $[34,35]$. In addition, $\mathrm{S}_{\lambda}$ refers to the sulfur state below $159^{\circ} \mathrm{C}$, which consists of $S_{8}$ molecules, while $S_{\mu}$ indicates an equilibrium mixture of $S_{\infty}$ and $S_{8}$ molecules, which can be obtained above $159^{\circ} \mathrm{C}$. In this study, the DSC was used to study the thermal behavior (i.e., phase transition of allotropic form of sulfur) of both elemental sulfur and SPC. Fig. 2 shows the results of the DSC analyses. In the case of elemental sulfur (red line), the first peak at $108.9^{\circ} \mathrm{C}$ indicates $\mathrm{S}_{\alpha}$ to $\mathrm{S}_{\beta}$ transition. The second major peak at $118.9^{\circ} \mathrm{C}$ and the last peak at $165^{\circ} \mathrm{C}$ show the $\mathrm{S}_{\beta}$ to $\mathrm{S}_{\gamma}$ transition and $\mathrm{S}_{\gamma}$ to $\mathrm{S}_{\mu}$ transition, respectively. The presence of polymeric sulfur was observable in the SPC. The significant reduction of the first peak is evidence that the solid phase transition is being suppressed due to sulfur polymerization [36]. In addition, the fusion of $\mathrm{S}_{\alpha}$ as observed by DSC was at a lower temperature $\left(102.0^{\circ} \mathrm{C}\right)$ than the elemental sulfur case $\left(108.9^{\circ} \mathrm{C}\right)$. The lower intensity of the third peak may be additional evidence of polymerization or an indication of a small quantity of unreacted sulfur presented in SPC sample. The slow, continual rising of the thermogram for the SPC is probably due to an unknown artifact that resided in the $\mathrm{Al}$ crucible. As mentioned previously, appropriately modified sulfur concrete does not go through allotropic transformation upon solidification $[4,13]$. Hence, it has less shrinkage 
upon cooling. Current DSC experiment confirms that the unstable solid phase transition at $108.9^{\circ} \mathrm{C}$ is evident in elemental sulfur. In contrast, almost no endotherm for the $\mathrm{S}_{\alpha}$ transition was found in the SPC.

\subsection{Crystallographic analysis}

$\mathrm{XRF}$ analysis was performed to determine the elemental composition of the SPC and a raw material of fly ash (Table 4). The converted elemental sulfur amount is $24.29 \mathrm{wt} . \%$, which is close to the amount of elemental sulfur in the mix design (i.e. $26 \mathrm{wt} . \%$ ). The low amount of $\mathrm{Ca}$ in fly ash indicates that used fly ash is fly ash type F. The large amount of Si in SPC is from fine aggregate (i.e., quartz). Undetected elements including oxygen are quantified as light elements (L.E.) in the Table 4.

The XRD pattern of elemental sulfur matches with the sulfur reference of ICSD\# 98-003-8147 as shown in Fig. 3(a). Since the obtained elemental sulfur is industrial by-product, some degree of misfit of peaks is expected. The observed peaks in the fly ash match the reference patterns for silicon oxide $\left(\mathrm{SiO}_{2}\right.$, 98-003-9830), mullite $\left(\mathrm{Al}_{6} \mathrm{Si}_{2} \mathrm{O}_{13}, 98009-9329\right)$, hematite $\left(\mathrm{Fe}_{2} \mathrm{O}_{3}, 98-002-2505\right)$, magnetite $\left(\mathrm{Fe}_{3} \mathrm{O}_{4}, 98\right.$ 003-5001), and corundum $\left(\mathrm{Al}_{2} \mathrm{O}_{3}, 98-005-6085\right)$. The reference structures for the identified phases were used to refine the relative phase fractions in the crystalline portion of fly ash and SPC. Zero shift, phase scale factors, background, and peak profile parameters were refined using X'pert HighScore Plus software [32]. The resulting fits of the calculated intensity from each phase to the corresponding observed data are shown in Fig. 3 and Table 5. The fits are relatively good with $\chi^{2}=3.5,1.1$, and 4.7 for elemental sulfur, fly ash, and SPC, respectively. As a next step, crystal structure refinement has been performed for elemental sulfur and sulfur crystal in SPC using the same software. The refined crystal structure of the elemental sulfur is orthorhombic (space group 70, $\alpha=\beta=\gamma=90^{\circ}, \mathrm{a}=10.45(7) \AA, \mathrm{b}=$ 12.85(9) $\AA, c=24.46(1) \AA)$. The crystal structure of sulfur in SPC was refined as $a=10.46(5) \AA, b=$ $12.86(6) \AA$, and $\mathrm{c}=24.48(1) \AA$.

The refined phase fractions in the crystalline portion of each sample are summarized in the Table 5. Initially, an internal standard material of $\mathrm{ZnO}(10 \%$ wt.) was mixed with ground SPC and fly ash, respectively to quantify amorphous content. Considering the amorphous content, the concentration of each phases in the sample was calculated based on standard quantitative analysis method [37]. The calculated concentrations are averaged from three time measurements on each samples (Table 5). Quantitative XRD refinement result of 23.1(5) wt.\% of sulfur is close with its amount in initial mix design (26\%). In addition, 18 wt.\% of amorphous phase, which was found as $70.9(7)$ wt.\% in fly ash, was detected. If there is no reaction between amorphous phase in fly ash and sulfur related phase transformation, the amorphous phase in SPC should be close to $12 \%$. The increase amount of amorphous 
phase can be explained by the addition of organic modifier and crystallographic modification of sulfur by polymerization. It has been reported that monoclinic sulfur phase can exist in modified sulfur concrete, which has less residual stresses upon cooling [3]. In this study, monoclinic crystal system of sulfur was not observed. However, the refinement of lattice parameters reveals that all three length lattice parameters of sulfur in SPC system were slightly increased compared to those in elemental sulfur. Similar peak shifting was observed in previous SPC study and explained as the change of grain size during sulfur polymerization [4]. The increased lattice parameters can be a direct evidence of sulfur polymerization by the ring-opening mechanism of sulfur atoms. Although we confirmed the change of lattice parameters of sulfur due to the modification as similar to previous study, additional ex-situ or insitu XRD study on sulfur at different temperatures can further elucidate this complex thermal behavior.

\subsection{Microscopy analysis}

From the micro-meter CT experiment, the total porosity was calculated as $4.9 \%$ and dominant pore diameters (in terms of the number) ranged from 20 to $100 \mu \mathrm{m}$. However, it was found out that pores larger than $100 \mu \mathrm{m}$ diameter mostly contribute to the total volumetric porosity in the tested sample (Fig. 6). The anisotropy analysis suggests that, although large pores in Fig. 5 seem to have round shapes, the large number of pores have non-circular shapes. If all pores are perfectly circular, the degree of anisotropy will be zero and all data points in Fig. $7(\mathrm{~b})$ will reside at $(1,1)$. The relatively spread distributions of I33/I11 and I22/I11 also confirms this trend.

Figs. 8(a) to (f) show collected SEM images. In general, the microstructure shows a considerable degree of packing with quartz (irregular large particles) and fly ash particles (round particles) bound together with sulfur. As expected from mix design proportion (Table 2), fine aggregates are dominant phases in the microstructure of SPC. The result of SEM-EDS analysis (not shown here) found fine aggregates and fly ash particles in Figs. 8(b) and (c). A previous SEM study on SPC showed uniformly distributed sulfur matrix $[3,4,11]$. We found out that some region is well covered with modified sulfur (Fig. 8(f)) while the modified sulfur phases are somehow separated and attached partially on the surface of bulk materials (Figs. 8(d) and (e)). Thus, it can be inferred that suitable covering of quartz and fly ash particles with modified sulfur can be an important factor to determine discrete void formation and a homogeneously robust microstructure. The uncovered quartz and fly ash can serve as a weak interfacial transition zone for SPC. The full covering may be achieved by increasing the amount of sulfur in the mix design or by changing the mixing conditions (i.e., mixing speed and temperature). 


\subsection{XANES analysis}

Spatially-resolved x-ray absorption near edge structure (XANES) spectroscopy at the sulfur Kedge was applied to the elemental sulfur and firstly to the SPC. The XANES technique has been widely used to characterize sulfur species because it is nondestructive and very sensitive to the electronic structure that allows it to reveal oxidation state and local symmetry of absorbing site [6, 28, 29, 38]. Nevertheless, the direct speciation and quantification of polymerized sulfur have not been elucidated yet. On the other hand, synchrotron based experiments are becoming popular to investigate the multi-scale structure of construction materials $[39,40]$. Since the size of the sulfur polymer matrix in concrete varies from a few to several tenths of micrometers (Fig. 9), spatially-resolved spectroscopy is necessary. For the first time, this study applies the spatially-resolved XANES spectroscopy for SPC.

Measured average spectra were corrected by subtracting the linear pre-edge background. Then, they were normalized to a post-edge step height of unity. Fig. 9(a) shows X-ray fluorescence map and spot locations for the XANES spectra. In the map, the high sulfur concentration area is dark whereas low sulfur concentration area is white. The spot positions of \#1 and \#2 result in small peaks compared to clear sulfur K-edge spectra in the other spots (Fig. 9(b)). Fig. 9(c) compares the XANES spectra in SPC (spot \#3-6) with that of elemental sulfur. All peaks were then normalized to their maximum peak heights of unity for the purpose of comparison. No changes of the absorption edge position $(2471.9 \mathrm{eV})$ indicate that the oxidation state of elemental sulfur (i.e., 0) has not been changed during polymerization. In addition, the spectra were found to be similar, indicating that they have similar atomic environments. Most importantly, the determination of sulfur polymerization was accomplished by observing the peak intensities. Figs. 9(c) and (d) confirm that the intensity of pre-edge shoulder was increased in the order of spot\# $3>6>5>4>$ elemental sulfur. This increase of peak intensity was interpreted as the evidence of sulfur polymerization [41]. Furthermore, the XRF contrast map of Fig. 9(a) supports this observation as a high sulfur concentration area (Spot \#3 and 6) and should have more polymerized sulfur than the others. Although the sulfur polymerization induced from the light catalytic cracking oil was qualitatively confirmed by XANES spectroscopy, further quantitative analysis (e.g., degree of sulfur polymerization) is still challenging due to the heterogeneous nature of the sample and the similarity of peak shapes. The sample, being relatively thick $(200 \mu \mathrm{m})$ and high concentration, also suffer from self-absorption effects that limit quantitative XANES analysis.

\section{Conclusions}


In this study, a new SPC using industrial by-products of sulfur, fly ash, and light catalytic cracking oil and fine aggregate was characterized. Since the developed SPC relies on an inexpensive

312 chemical modifier (i.e., also a by-product from oil refineries), this material can be a practical and cost-

313 effective solution for a sustainable construction material.

It was confirmed that sulfur polymerization induced from the light catalytic cracking oil under high temperature has satisfactory binding capacity to hold fly ash and fine aggregate. The measured mechanical properties exceeded those for most construction applications. The DSC experiments on elemental sulfur and SPC indicate a reduced endothermic reaction of $\mathrm{S}_{\alpha}$ and thus a successful polymerization reaction. The XRD experiment revealed that the length lattice parameters of sulfur (i.e., a, $\mathrm{b}$, and c) were slightly stretched due to the polymerization.

X-ray CT, a non-invasive 3-dimentional image technique, provided total porosity of $4.9 \%$. Although pore diameters ranging between 20 to $100 \mu \mathrm{m}$ are the most abundant, pores larger than $100 \mu \mathrm{m}$ diameter mostly contributes to the total volumetric porosity in SPC system. Furthermore, as opposed to the visual inspection of pores, large number of pores has non-circular shapes in SPC system. In addition, spatially-resolved XANES spectroscopy qualitatively revealed the polymerization in the developed SPC. Furthermore, the current experiment demonstrates that spatially-resolved XANES spectroscopy is a viable characterization technique to identify the non-uniformly distributed sulfur polymerization in sulfur polymer cement materials.

A series of performed experiments herein successfully evaluated a new possible sustainable concrete which has low carbon footprint and environmental impact. The characterization results herein will be used for further optimization of this new SPC. Additional durability testing including freeze-thaw cycling is planned to confirm the long-term durability.

\section{Acknowledgments}

We want to acknowledge W. Fang, T. Gyephel, and A. Thompson for their help on SEM and CT experiments. This research was funded by Award No. NSF-SBIR 13-546. Experiments were partly carried out at the Center for Functional Nanomaterials and National Synchrotron Light Source, Brookhaven National Laboratory, which are supported by the U.S. Department of Energy (DOE), Office of Basic Sciences, Office of Basic Energy Sciences, under contract no. DE-SC0012704. The X15B National Science Foundation (Earth Science Instrumentation and Facilities), and NASA (LARS). 
[1] Worrell E, Price L, Martin N, Hendriks C, Meida LO. Carbon dioxide emissions from the global cement industry 1. Annual Review of Energy and the Environment. 2001;26(1):303-29.

[2] Agency IE. Cement Technology Roadmap 2009, Carbon Emission Reductions up to 2050. World Business Council for Sustainable Development, 2009, www.ieaorg. 2009.

[3] Mohamed A-MO, El-Gamal M. Sulfur concrete for the construction industry: a sustainable development approach: J. Ross Publishing; 2010.

[4] Mohamed A-MO, El Gamal M. Sulfur based hazardous waste solidification. Environmental geology.

$350 \quad 2007 ; 53(1): 159-75$.

351 [5] Kalb P, Heiser III J, Pietrzak R, Colombo P. Durability of incinerator ash waste encapsulated in modified sulfur cement. Brookhaven National Lab., Upton, NY (USA). Funding organisation: USDOE, Washington, DC (USA); 1991. sulphur in petroleum asphaltenes by X-ray absorption spectroscopy. Fuel. 1992;71(1):53-7. [7] 548 AC. Guide for Mixing and Placing Sulfur Concrete in Construction. ACI Materials Journal. 1988;85(4). on polymers in concrete1992. p. 606-21.

[9] Nnabuife E. Study of some variables affecting the properties of sulfur-reinforced sugarcane residuebased boards. Indian Journal of Technology. 1987;25(8):363-7. dicyclopentadiene. Advances in chemistry series. 1978(165):31-53. concrete. Cement and Concrete Composites. 2009;31(3):186-94. polymer concrete. Reclaiming the Desert: Towards a Sustainable Environments in Arid Land. Developments in Arid Region Research (DARE), Taylor and Francis Group, London, ISBN. 2006;414411289:27-38. (S/S) process. Waste management. 1995;15(5):441-7.

372 [14] Fuhrmann M, Melamed D, Kalb P, Adams J, Milian L. Sulfur polymer solidification/stabilization of elemental mercury waste. Waste Management. 2002;22(3):327-33.

[15] Kalb P, Heiser III J, Colombo P. Comparison of modified sulfur cement and hydraulic cement for encapsulation of radioactive and mixed wastes. 1990.

[16] Darnell G. Sulfur polymer cement, a new stabilization agent for mixed and low-level radioactive waste. EG and G Idaho, Inc., Idaho Falls, ID (United States); 1991.

378 [17] Currell B. The importance of using additives in the development of new applications for sulfur.

379 Symposium on new users for sulfur and pyrites, Madrid1976. p. 105-3.

380 [18] Beaudoin J, Feldman RF. Durability of porous systems impregnated with dicyclopentadiene-

381 modified sulphur. International Journal of Cement Composites and Lightweight Concrete. 1984;6(1):13-8.

382 [19] Vroom AH. Sulphur cements, process for making same and sulphur concretes made therefrom.

383 Google Patents; 1981. 
[20] V. P. Vagin PDK, and S.P. Vagin. Method of Making Stable Sulfur Binding Using Activated Fillers (SSBAF). Russian Patent No 2011/126263 (December 2013); Kazakhstan Patent No 27805 (Jan 2014); Chinese Patent No 2009801553273 (August 2014); US Patent Pending. [21] D5554-15 A. Standard Test Method for Determination of the lodine Value of Fats and Oils. ASTM International. 2015; www.astm.org(West Conshohocken, PA).

[22] D86-12 A. Standard Test Method for Distillation of Petroleum Products at Atmospheric Pressure. ASTM International. 2012; www.astm.org(West Conshohocken, PA).

[23] Mohamed A. Hydro-mechanical evaluation of soil stabilized with cement-kiln dust in arid lands. Environmental Geology. 2002;42(8):910-21.

[24] Moon J, Bae S, Celik K, Yoon S, Kim K-H, Kim KS, et al. Characterization of natural pozzolan-based geopolymeric binders. Cement and Concrete Composites. 2014;53:97-104.

[25] Blow J, Binstock AJ. How to find the inertia tensor (or other mass properties) of a 3D solid body represented by a triangle mesh. 2004. 2004.

[26] Drach B, Drach A, Tsukrov I. Characterization and statistical modeling of irregular porosity in carbon/carbon composites based on X-ray microtomography data. ZAMM-Journal of Applied Mathematics and Mechanics/Zeitschrift für Angewandte Mathematik und Mechanik. 2013;93(5):346-66. [27] Sarret G, Connan J, Kasrai M, Bancroft GM, Charrié-Duhaut A, Lemoine S, et al. Chemical forms of sulfur in geological and archeological asphaltenes from Middle East, France, and Spain determined by sulfur K-and L-edge X-ray absorption near-edge structure spectroscopy. Geochimica et Cosmochimica Acta. 1999;63(22):3767-79.

[28] Xia K, Weesner F, Bleam W, Helmke P, Bloom P, Skyllberg U. XANES studies of oxidation states of sulfur in aquatic and soil humic substances. Soil Science Society of America Journal. 1998;62(5):1240-6.

[29] Morra MJ, Fendorf SE, Brown PD. Speciation of sulfur in humic and fulvic acids using X-ray absorption near-edge structure (XANES) spectroscopy. Geochimica et Cosmochimica Acta. 1997;61(3):683-8.

409 [30] Vairavamurthy A, Manowitz B, Luther lii G, Jeon Y. Oxidation state of sulfur in thiosulfate and implications for anaerobic energy metabolism. Geochimica et cosmochimica acta. 1993;57(7):1619-23. [31] Chae SR, Moon J, Yoon S, Bae S, Levitz P, Winarski R, et al. Advanced nanoscale characterization of cement based materials using $\mathrm{X}$-ray synchrotron radiation: a review. International Journal of Concrete Structures and Materials. 2013;7(2):95-110.

[32] Jackson MD, Moon J, Gotti E, Taylor R, Chae SR, Kunz M, et al. Material and Elastic Properties of Al-Tobermorite in Ancient Roman Seawater Concrete. Journal of the American Ceramic Society. 2013. [33] Jackson MD, Chae SR, Mulcahy SR, Meral C, Taylor R, Li P, et al. Unlocking the secrets of Altobermorite in Roman seawater concrete. Am Mineral. 2013;98.

[34] Kelemen S, George G, Gorbaty M. Direct determination and quantification of sulphur forms in heavy petroleum and coals: 1. The X-ray photoelectron spectroscopy (XPS) approach. Fuel. 1990;69(8):939-44. [35] Currell B, Williams A. Thermal analysis of elemental sulphur. Thermochimica Acta. 1974;9(3):255-9. [36] McBee WC, Sullivan TA, Jong B. Modified-sulfur cements for use in concretes, flexible pavings, coatings, and grouts. NASA STI/Recon Technical Report N. 1981;82:11333.

[37] Scrivener K, Füllmann T, Gallucci E, Walenta G, Bermejo E. Quantitative study of Portland cement hydration by X-ray diffraction/Rietveld analysis and independent methods. Cement and Concrete Research. 2004;34(9):1541-7.

[38] Gorbaty ML, George GN, Kelemen SR. Direct determination and quantification of sulphur forms in heavy petroleum and coals: 2 . The sulphur K edge X-ray absorption spectroscopy approach. Fuel. 1990;69(8):945-9.

[39] Moon J, Speziale S, Meral C, Kalkan B, Clark SM, Monteiro PJ. Determination of the elastic properties of amorphous materials: Case study of alkali-silica reaction gel. Cement and Concrete 431 Research. 2013;54:55-60. 
432 [40] Moon J-h, Oh JE, Balonis M, Glasser FP, Clark SM, Monteiro PJ. Pressure induced reactions amongst 433 calcium aluminate hydrate phases. Cement and Concrete Research. 2011;41(6):571-8.

434 [41] Prange A, Chauvistré R, Modrow H, Hormes J, Trüper HG, Dahl C. Quantitative speciation of sulfur in 435 bacterial sulfur globules: X-ray absorption spectroscopy reveals at least three different species of sulfur. 436 Microbiology. 2002;148(1):267-76.

437 
Table 1. ASTM D86 characterization of used light catalytic cracking oil

\begin{tabular}{cc}
\hline Parameter & Temperature $^{\circ} \mathrm{F}$ \\
\hline Initial boiling point & 335.4 \\
5\% Recovery & 433.3 \\
10\% Recovery & 453.1 \\
20\% Recovery & 482 \\
30\% Recovery & 495.8 \\
40\% Recovery & 507 \\
50\% Recovery & 520.1 \\
60\% Recovery & 534.8 \\
70\% Recovery & 553.1 \\
80\% Recovery & 576.6 \\
90\% Recovery & 612.2 \\
95\% Recovery & 641 \\
Final boiling point & 660.6 \\
\hline
\end{tabular}

Table 2. Mixture proportion of sulfur polymer concrete

\begin{tabular}{cccccc}
\hline Oxide & Sulfur & Sand & Fly ash & Organic modifier & Total \\
\hline wt.\% & 26 & 54 & 18 & 2 & 100
\end{tabular}

Table 3. Mechanical testing results

\begin{tabular}{ccc}
\hline & $20{ }^{\circ} \mathrm{C}$ & $50{ }^{\circ} \mathrm{C}$ \\
\hline Avg. Compressive Strength (MPa) & $62.3(3.8)$ & $59.6(4.5)$ \\
\hline Avg. Flexural Strength (MPa) & $8.1(1.1)$ & $8.0(2.0)$ \\
\hline
\end{tabular}

Table 4. Elemental composition (wt.\%) of sulfur polymer concrete

\begin{tabular}{|c|c|c|c|c|c|c|c|c|c|c|c|c|}
\hline & $\mathrm{Na}$ & $\mathrm{Mg}$ & Al & $\mathrm{Si}$ & $P$ & $S$ & K & $\mathrm{Ca}$ & $\mathrm{Ti}$ & $\mathrm{Fe}$ & L.E. & Total \\
\hline Fly ash & 0.35 & 0.37 & 13.23 & 23.75 & 0.08 & 0.24 & 1.93 & 1.84 & 0.74 & 7.45 & 49.98 & 100 \\
\hline Sulfur polymer concrete & 0.18 & 0.15 & 1.62 & 15.71 & 0.12 & 24.29 & 0.27 & 0.33 & 0.11 & 0.55 & 56.57 & 100 \\
\hline
\end{tabular}

*Note: L.E. indicates light elements including oxygen and carbon. 
Table 5. Phase calculation from quantitative X-ray diffraction

\begin{tabular}{c|c|cc|cc}
\hline \multirow{2}{*}{ Identified Phases } & \multirow{2}{*}{ ICSD\# } & \multicolumn{2}{|c|}{ Measured weight (\%) } & \multicolumn{2}{c}{ Calculated weight (\%) } \\
& & Fly ash & SPC & Fly ash & SPC \\
\hline Sulfur (S) & $98-003-8147$ & 0.0 & $25(1)$ & 0.0 & $23.1(5)$ \\
Silicon oxide-alpha $\left(\mathrm{SiO}_{2}\right)$ & $98-003-9830$ & $20.1(4)$ & $58.5(8)$ & $8.1(1)$ & $54.1(1)$ \\
Mullite $\left(\mathrm{Al}_{6} \mathrm{Si}_{2} \mathrm{O}_{13}\right)$ & $98-009-9329$ & $45(2)$ & $3.0(5)$ & $18.0(5)$ & $2.7(4)$ \\
Hematite $\left(\mathrm{Fe}_{2} \mathrm{O}_{3}\right)$ & $98-002-2505$ & $6(1)$ & $0.5(5)$ & $2.4(4)$ & $0.5(5)$ \\
Magnetite $\left(\mathrm{Fe}_{3} \mathrm{O}_{4}\right)$ & $98-003-5001$ & $0.8(2)$ & $0.3(3)$ & $0.3(1)$ & $0.3(3)$ \\
Corundum $\left(\mathrm{Al}_{2} \mathrm{O}_{3}\right)$ & $98-005-6085$ & $0.6(3)$ & $0.2(3)$ & $0.2(1)$ & $0.2(2)$ \\
Zinc oxide $(\mathrm{ZnO})$ & $98-009-4004$ & $27.7(5)$ & $12.0(2)$ & - & - \\
Amorphous content & N.A. & - & - & $70.9(7)$ & $18(1)$ \\
\hline
\end{tabular}



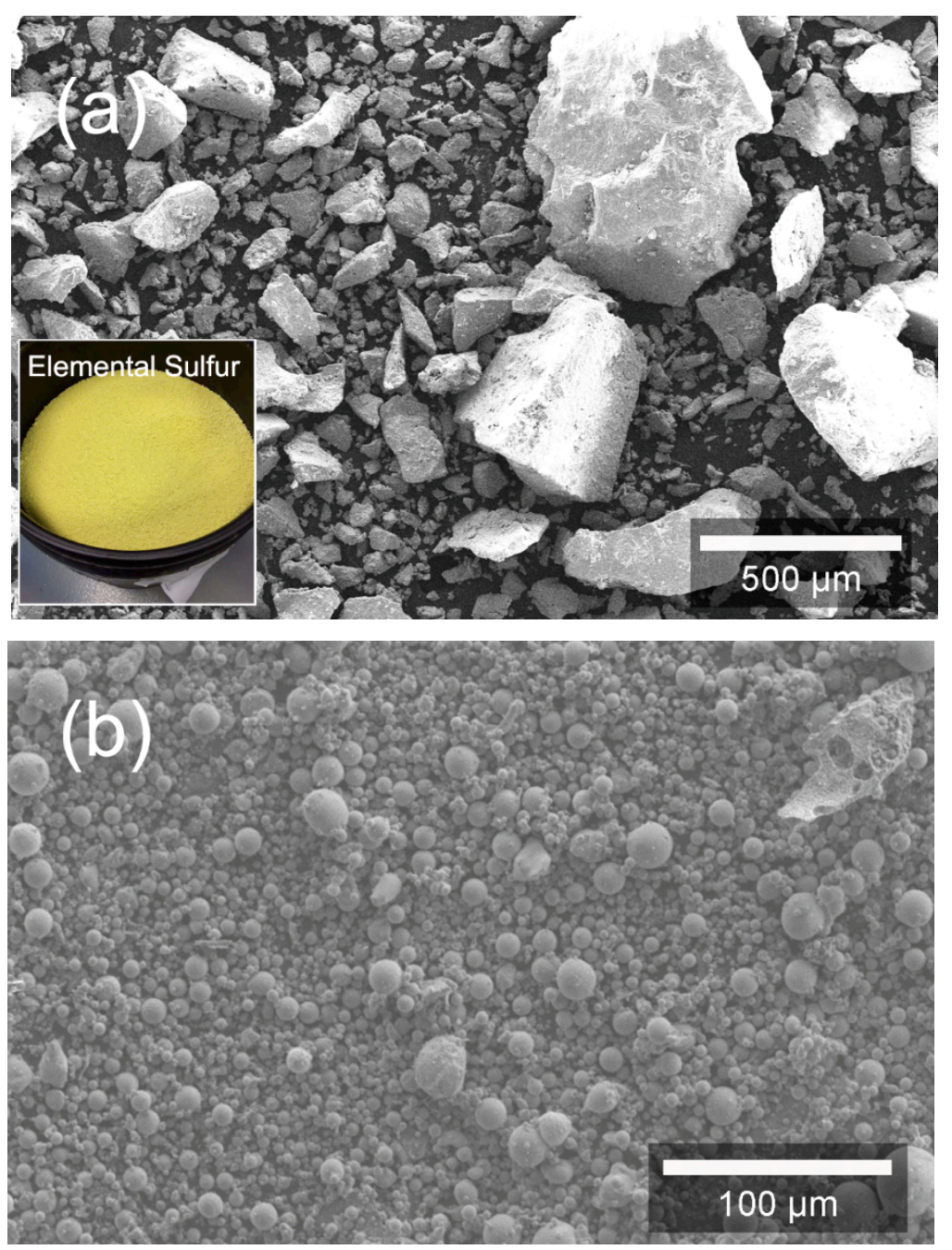

Figure 1. SEM images of (a) ground elemental sulfur and (b) fly ash. 


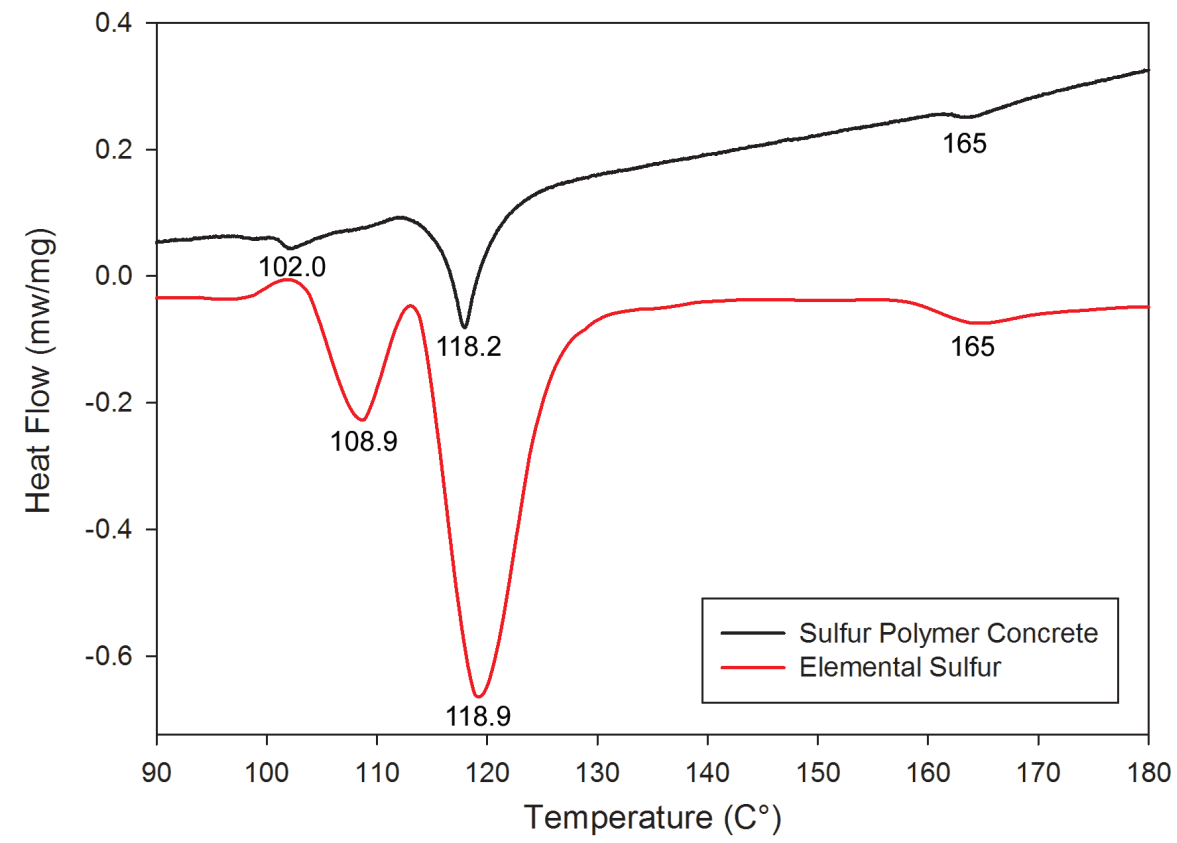

Figure 2. Thermal properties of elemental sulfur and sulfur polymer concrete. 


\section{(a)}
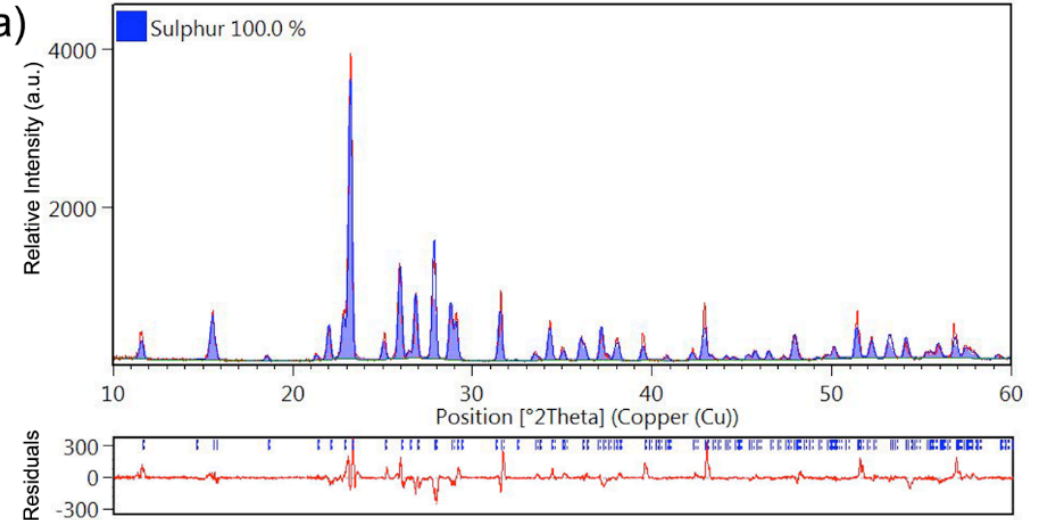

(b)
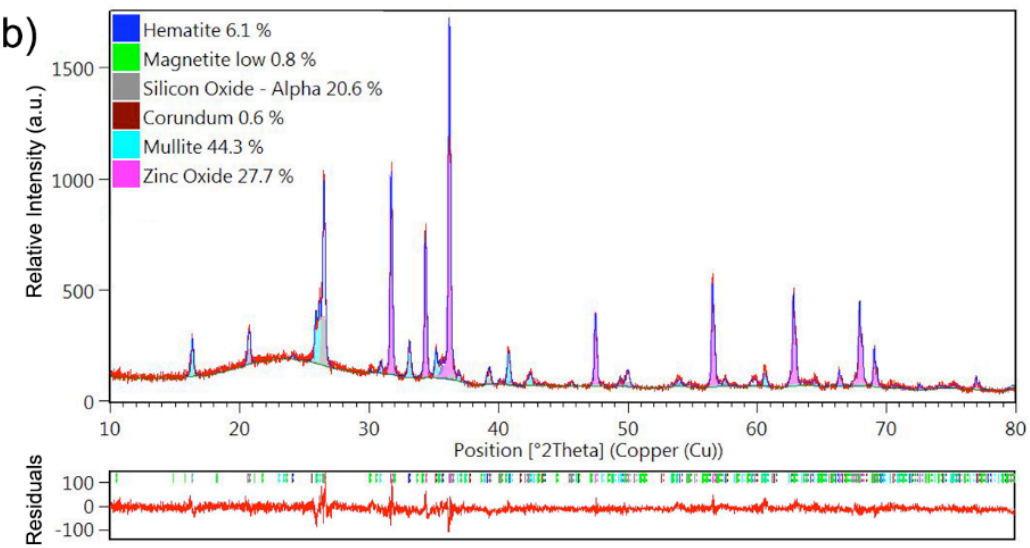

(c)
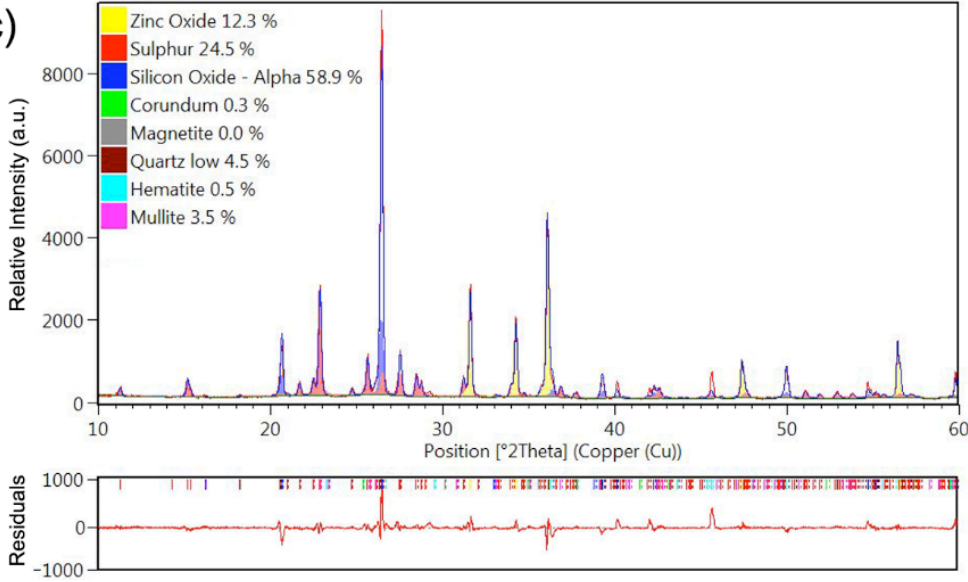

Figure 3. Quantitative X-ray diffraction of (a) elemental sulfur, (b) fly ash, and (c) sulfur polymer concrete. $\mathrm{ZnO}$ powder was used for internal standard. 


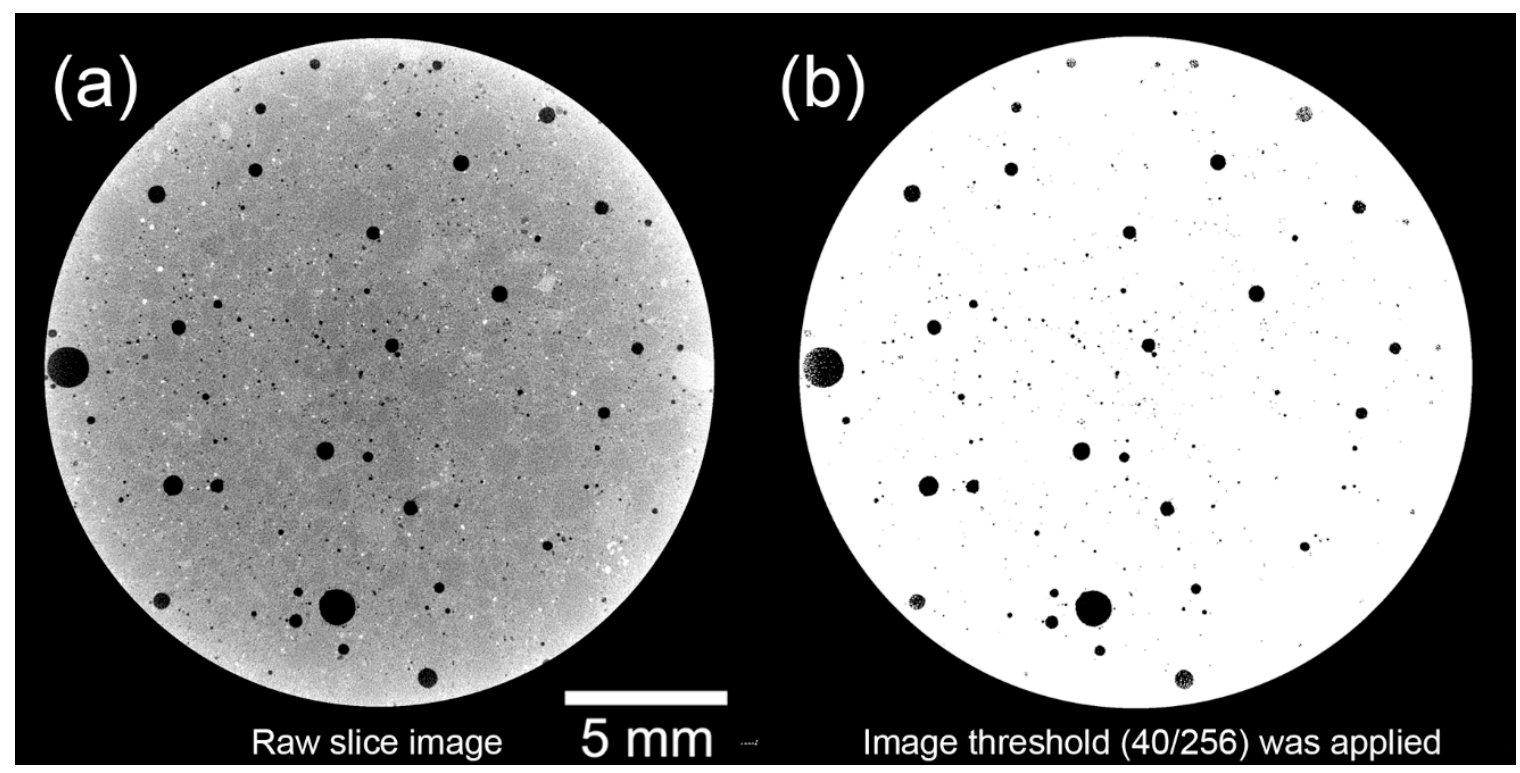

Figure 4. 2D reconstructed slice images from micro-CT experiment; (a) raw image and (b) pore segmented image with a threshold value of $40 / 256$.
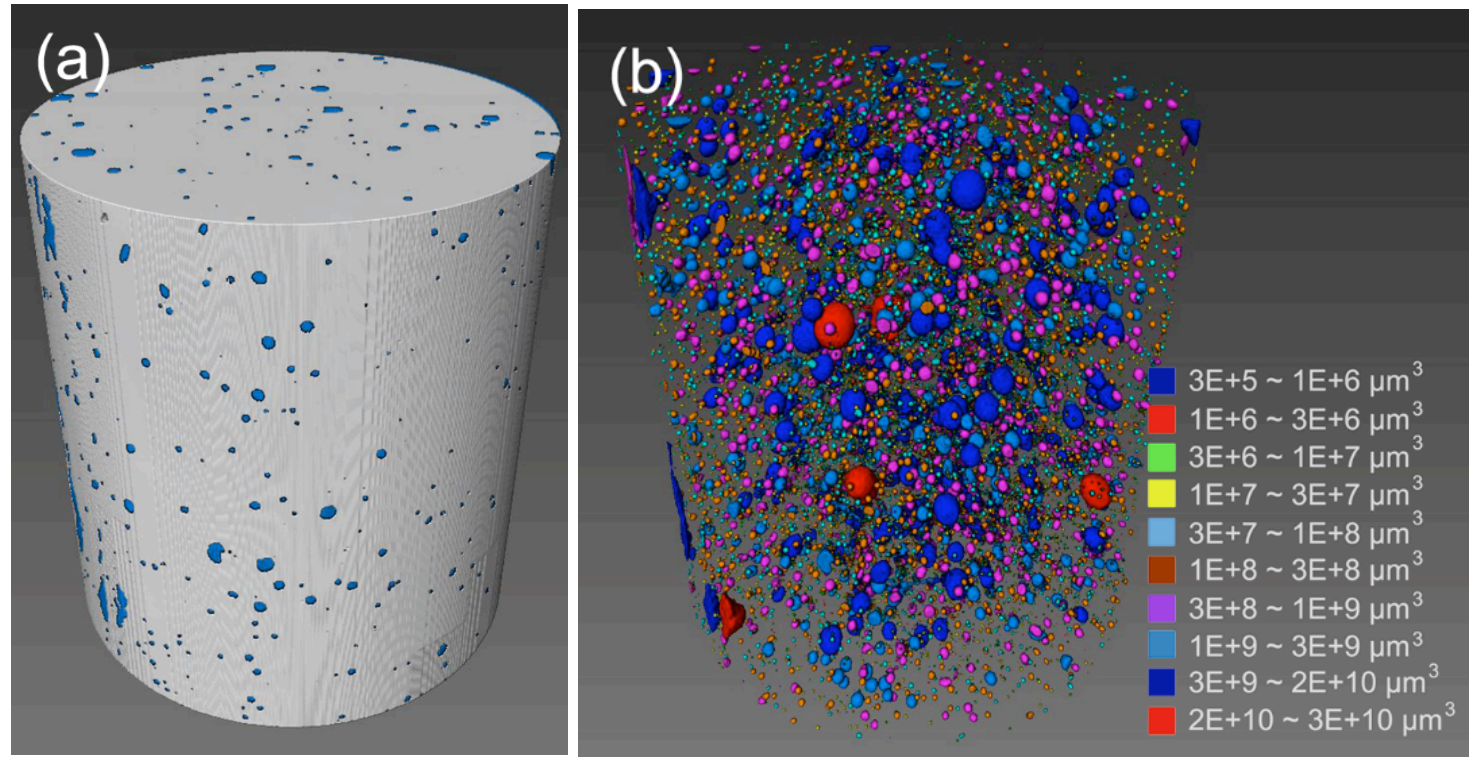

Figure 5. 3D reconstructed volumetric images; (a) pore segmentation and (b) pore visualization based on computed volume. The sample dimension is $25 \mathrm{~mm}$ diameter and $50 \mathrm{~mm}$ height. 

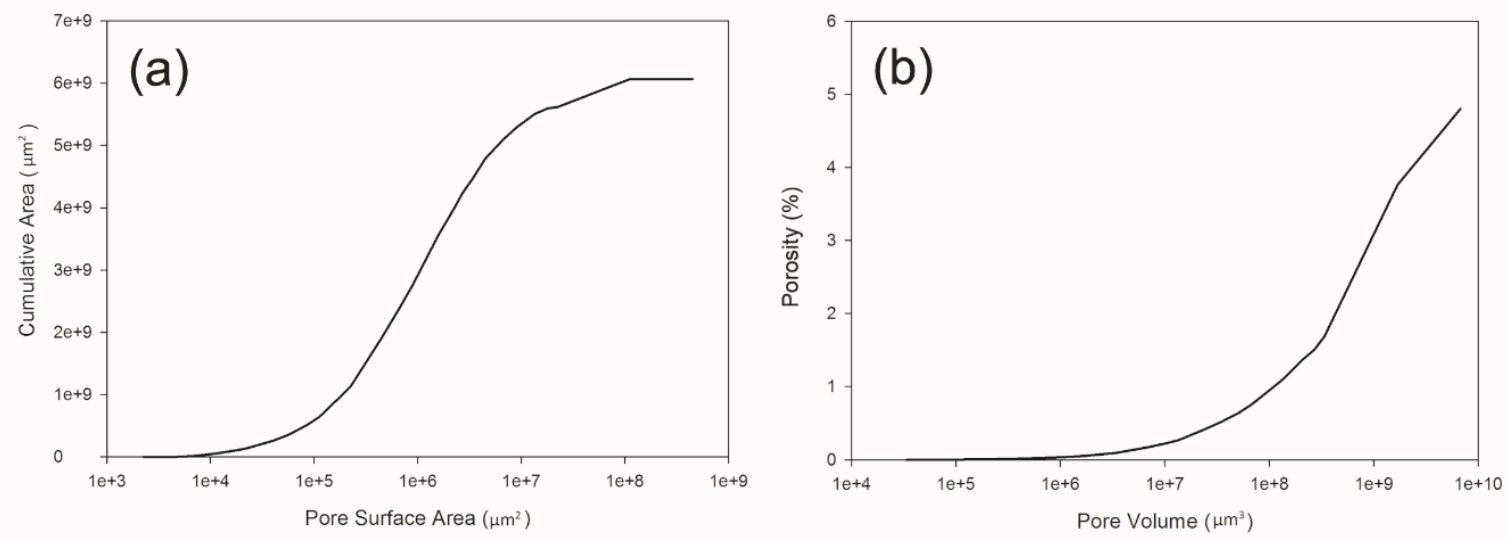

Figure 6. Cumulative distributions of (a) pore surface area and (b) pore volume.
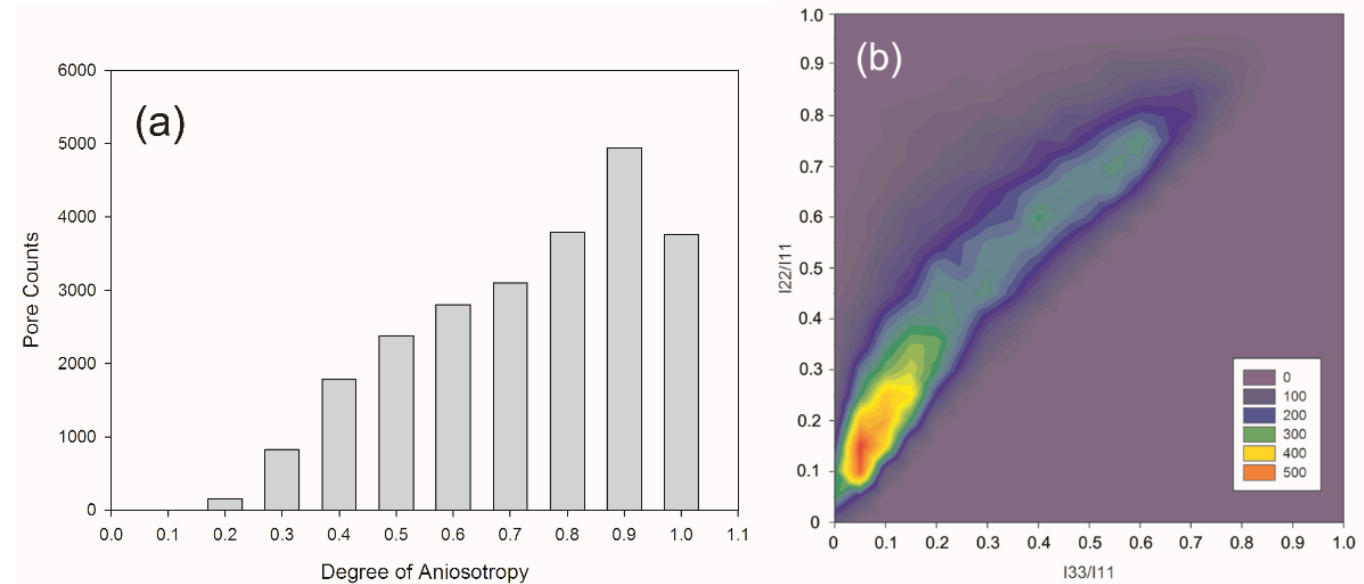

Figure 7. Histograms of (a) pore anisotropy and (b) distribution of I22/I11 and I33/I11. 

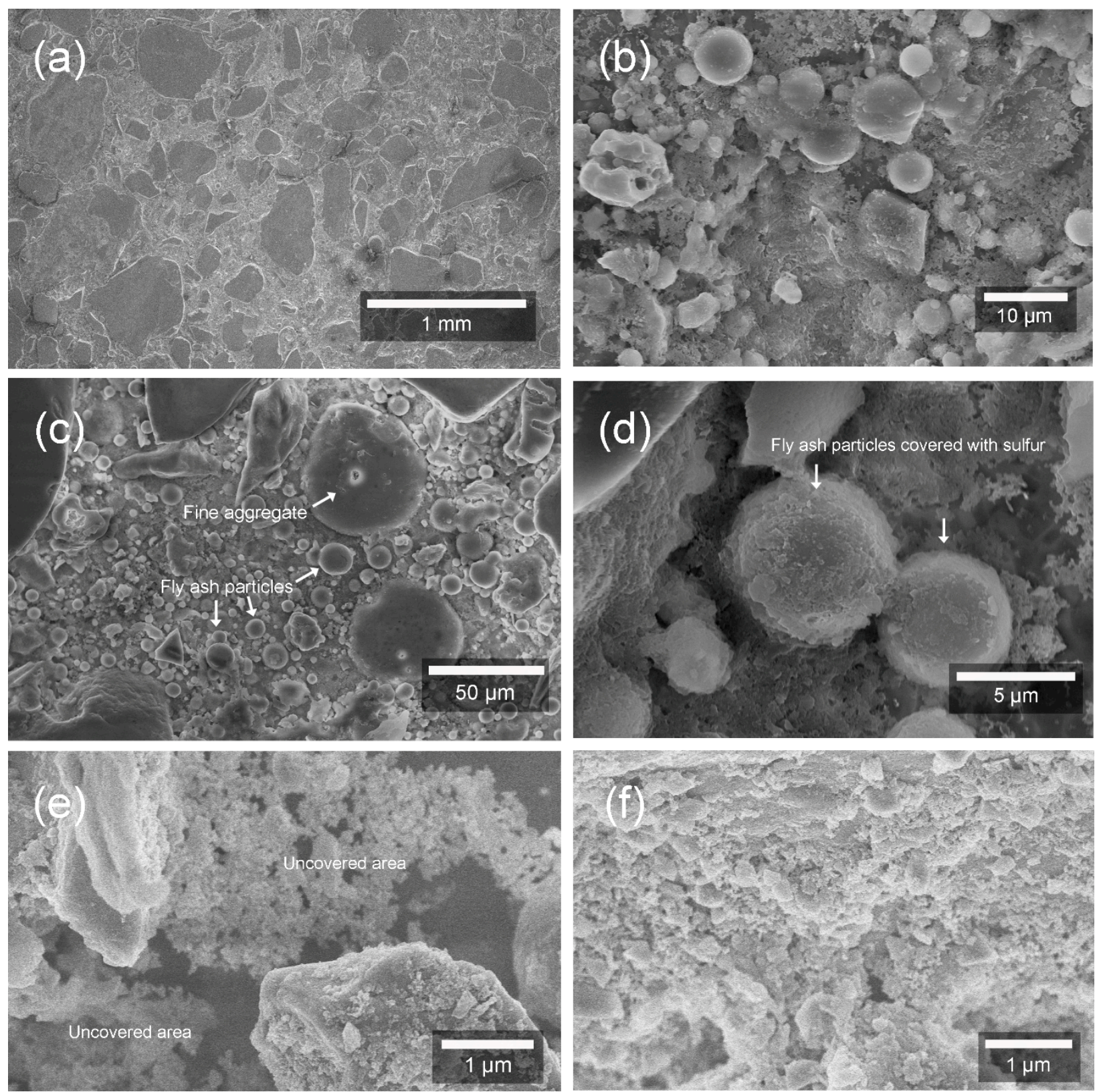

Figure 8. Microscopic images from SEM measurement. 

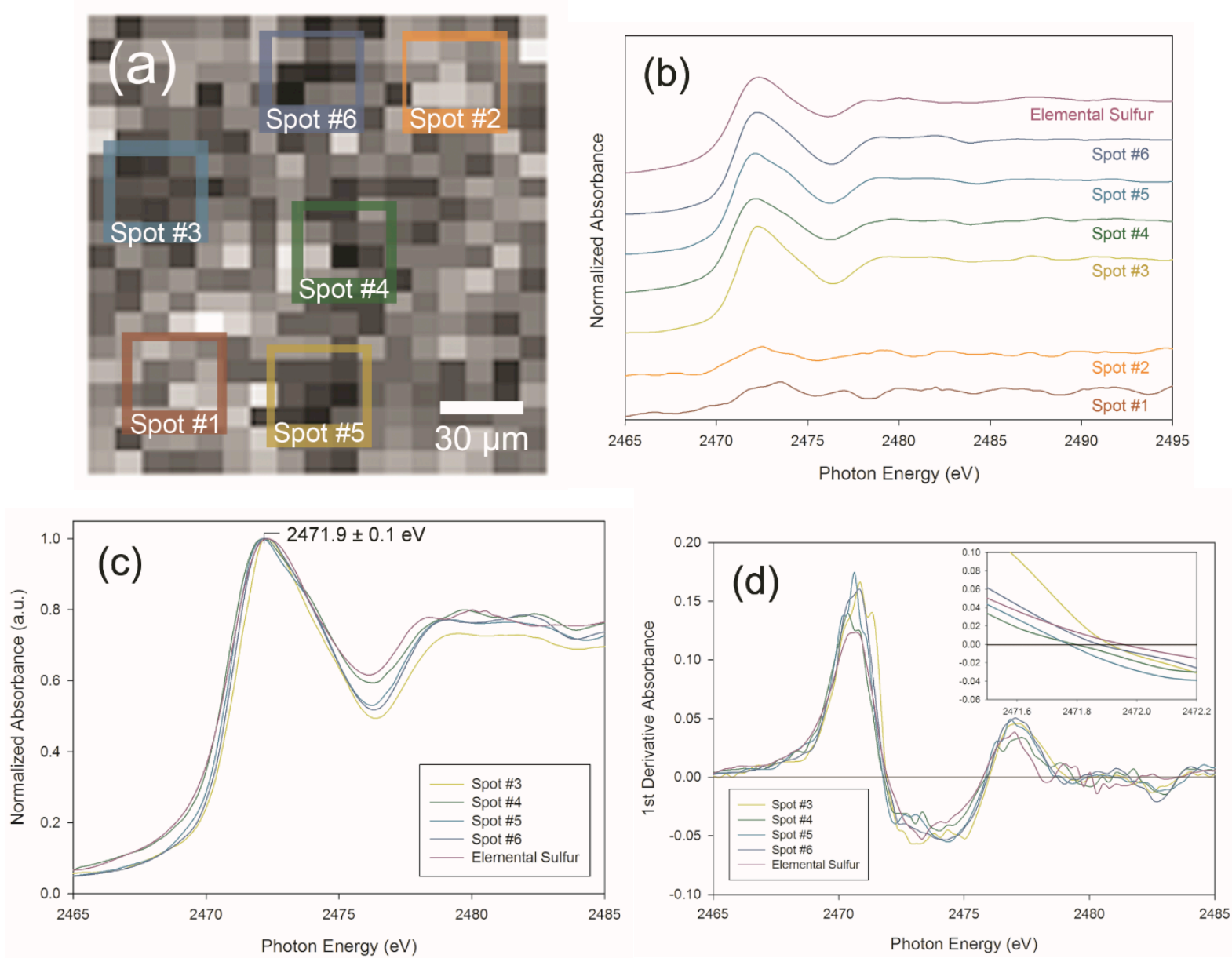

Figure 9. X-ray absorption near-edge spectroscopy (XANES) results; (a) mapping area, (b) X-ray absorption stack patterns of sulfur polymer concrete (spot \#1-6) and elemental sulfur (purple), (c) normalized absorbance, and (d) first derivative absorbance. 